\title{
Article \\ Carbon Black/Polyvinylidene Fluoride Nanocomposite Membranes for Direct Solar Distillation
}

\author{
Marcello Pagliero 1,2,*D, Marina Alloisio ${ }^{1}$ (D), Camilla Costa ${ }^{1,2}$, Raffaella Firpo ${ }^{1,2}$, \\ Ermias Ararsa Mideksa ${ }^{1}$ (D) and Antonio Comite ${ }^{1,2}$ (D)
}

1 Department of Chemistry and Industrial Chemistry, University of Genoa, Via Dodecaneso 31, 16146 Genova, Italy; marina.alloisio@unige.it (M.A.); camilla.costa@unige.it (C.C.); raffaella.firpo@unige.it (R.F.); ermiasararsa@gmail.com (E.A.M.); antonio.comite@unige.it (A.C.)

2 INSTM, Udr di Genova, Via Dodecaneso 31, 16146 Genova, Italy

* Correspondence: marcello.pagliero@unige.it

check for updates

Citation: Pagliero, M.; Alloisio, M.; Costa, C.; Firpo, R.; Mideksa, E.A.; Comite, A. Carbon Black/ Polyvinylidene Fluoride Nanocomposite Membranes for Direct Solar Distillation. Energies 2022, 15, 740. https://doi.org/ $10.3390 /$ en 15030740

Academic Editor: Alessandra Criscuoli

Received: 17 December 2021

Accepted: 17 January 2022

Published: 20 January 2022

Publisher's Note: MDPI stays neutral with regard to jurisdictional claims in published maps and institutional affiliations.

Copyright: (c) 2022 by the authors. Licensee MDPI, Basel, Switzerland. This article is an open access article distributed under the terms and conditions of the Creative Commons Attribution (CC BY) license (https:/ / creativecommons.org/licenses/by/ $4.0 /)$.

\begin{abstract}
Water reclamation is becoming a growing need, in particular in developing countries where harvesting the required energy can be a challenging problem. In this context, exploiting solar energy in a specifically tailored membrane distillation (MD) process can be a viable solution. Traditional MD guarantees a complete retention of non-volatile compounds and does not require high feed water temperatures. In this work, a suitable amount of carbon black (CB) was incorporated into the whole matrix of a polymeric porous membrane in order to absorb light and directly heat the feed. The mixed matrix membranes were prepared forming a uniform CB dispersion in the PVDF dope solution and then using a non-solvent induced phase separation process, which is a well-established technique for membrane manufacturing. CB addition was found to be beneficial on both the membrane structure, as it increased the pore size and porosity, and on the photothermal properties of the matrix. In fact, temperatures as high as $60^{\circ} \mathrm{C}$ were reached on the irradiated membrane surface. These improvements led to satisfactory distillate flux (up to $2.3 \mathrm{~L} / \mathrm{m}^{2} \mathrm{~h}$ ) during the direct solar membrane distillation tests performed with artificial light sources and make this membrane type a promising candidate for practical applications in the field of water purification.
\end{abstract}

Keywords: carbon black; photothermal; direct solar membrane distillation; PVDF; renewable energy

\section{Introduction}

Membrane distillation (MD) is a thermally driven separation process based on a hydrophobic porous membrane which contacts a hot concentrated solution and pure water. The temperature difference applied at each side of the membrane induces a vapor pressure difference across the membrane that acts as driving force for the process and establishes a water vapor flux from the hot to the cold section $[1,2]$.

Membranes used for MD application must comply with important specific requirements. First, high porosity is mandatory to maximize the trans-membrane water flux since the mass transfer coefficient is proportional to the mean porosity of the membrane itself [3]. Another essential feature is good surface hydrophobicity. In fact, the pores need to remain dry during MD operation since their flooding can cause a decrease of the distillate flux, as well as a reduction of the separation ability of the membrane [4,5]. This property can be controlled either by decreasing the surface wettability or by developing membranes with small pores and a narrow pore size distribution. Smaller pores are indeed less prone to wetting phenomena [6].

MD membranes exist in two basic configurations: hollow fiber and flat sheet. They can be arranged in different modules $[7,8]$ and are generally prepared using hydrophobic polymers, such as polypropylene $[9,10]$, polyethylene [11], polytetrafluoroethylene (PTFE) $[12,13]$ and polyvinylidene fluoride (PVDF) [14-17], or using modified ceramic materials [18-20]. Among all of the aforementioned materials, PVDF is particularly attractive 
because it can be easily dissolved in most common organic solvents so membranes can be prepared via traditional processes, such as thermally induced phase separation (TIPS) and non-solvent induced phase separation (NIPS) [21].

Four main configurations of MD have been developed, namely direct contact MD (DCMD), sweeping gas MD (SGMD), air gap MD (AGMD) and vacuum MD (VMD). The main differences among these configurations reside in the distillate section of the equipment [22].

In this work, VMD configuration has been used to assess the performance of the prepared membranes. In this mode, a partial vacuum pressure is applied on the distillate side of the membrane to remove the water vapor molecules from the membrane module. Since the partial water vapor pressure is constantly maintained as low as possible, VMD guarantees the highest fluxes among all of the MD configurations and reduces the heat losses correlated to heat conduction through the membrane. However, in some conditions, the net pressure difference across the membrane can favor pore flooding, possibly causing a reduction of the process productivity and separation ability $[2,23]$.

Nowadays, MD is a mature technology and it appears to be one of the best technologies for developing off-grid desalination/wastewater treatment plants due to its modular configuration, low power consumption and ability to harness low-grade energy resources [24].

An important problem affecting MD scale up is the heat loss associated to water evaporation in the feed section along the surface of the membrane module. The phase transition that takes place at the feed/pore interface reduces the temperature of water flowing along the module in the feed channel, gradually decreasing the effective driving force of the process [25]. This effect in practice limits the maximum length of the membrane module. An effective solution to contain the feed temperature reduction along the membrane module recently developed is the so-called membrane localized heating that can be obtained using several different techniques. Tan et al. [26], for example, harnessed the high thermal conductivity of nickel and its capacity to be inductively heated by placing a nickel foam in the feed channel of the membrane cell in place of a traditional plastic spacer. The advantage was the possibility of increasing the foam temperature by electromagnetic induction, and therefore heating the feed directly inside the membrane cell. Experimental tests proved that this arrangement was able to improve the energy efficiency and the productivity of the DCMD process. A similar solution was followed by Anvari et al. [27] who spray-coated a commercial PTFE membrane with a layer containing multiwall carbon nanotubes coated with iron oxide. This added layer had magnetic properties that allowed for providing inductive heating directly on the surface of the membrane. It was observed that increasing the nanoparticles loading and the feed residence time improved the distillate flux since heat transfer from the membrane to the feed solution was enhanced. Moreover, these membranes showed high efficiency for feed solutions containing highly saline solutions, proving that this process can be applied to traditional brine treatment.

A particular approach recently explored aims to achieve localized heating by harnessing solar energy. One of the main advantages of the direct solar membrane distillation (DSMD) layout is that the feed temperature is raised in the boundary layer in contact with the membrane surface. Therefore, temperature polarization effects are drastically reduced, and the effective driving force of the process is increased [28]. The DSMD process has been proposed by many researchers as an effective solution to developing larger MD plants [29-31]. The basic solar MD setup consists of a photovoltaic panel used to provide the electrical current required to run the feed water circulation system, and a solar collector that is used to heat the feed. However, this simple configuration is characterized by some flaws, namely the heat losses along the pipes connecting the feed tank to the membrane cell and the need for large solar collectors to reach an adequate feed temperature [32]. Said et al. [28] recently tested a DSMD small pilot plant, assessing its performance in real life operation conditions. The plant was completely powered by solar energy, with a photovoltaic panel providing the electricity for feed circulation and a $0.12 \mathrm{~m}^{2}$ photoactive membrane cell. 
During the testing time the plant mean distillate flux reached $0.55 \mathrm{~L} / \mathrm{m}^{2} \mathrm{~h}$ with a rejection factor of $99.8 \%$.

The main research efforts on the development of photoactive membranes for DSMD have been focused at present on the surface modification of commercial hydrophobic membranes; many researchers have coated membrane surfaces with an additional layer containing different fillers, such as carbon nanotubes [33] or carbon black (CB) [28,34-36] and silica-gold nanoparticles [35]. In particular, Wu et al. [35] created a layer composed of polyvinyl alcohol containing carbon black or silica-gold nanospheres. CB-coated membranes showed an increase of $33 \%$ in distillate flux when irradiated with solar-like light, while membranes treated with silica-gold nanoparticles produced a more limited improvement of $17 \%$.

In this work, a novel approach was adopted, i.e., hydrophobic photoactive membranes were autonomously prepared in our laboratory, including carbon black directly inside the starting bulk of the polymeric matrix rather than adding a supplementary layer on a preformed membrane. These original nanocomposite membranes were then produced easily with a common NIPS technique. The aim of this study was to explore the effect of the filler on the membrane photothermal properties, as well as on the membrane's internal structure. The influence of $\mathrm{CB}$ loading on the MD performance was investigated. To the best of our knowledge, intrinsically photoactive membranes of this particular kind, intended for direct solar membrane distillation, have not been prepared and studied before.

\section{Material and Methods}

\subsection{Dope Solution and Photoactive Membrane Preparation}

The membrane type studied in this work was prepared in our laboratory through a method described in a previous article [37]. CB (Vulcan XC72R, Cabot Corp-Boston, MA, USA, primary particle size: $30-60 \mathrm{~nm}$ [38]) was first dispersed in a green organic solvent (i.e., triethyl phosphate, TEP, Merck-Darmstadt, Germany). To this end, a precise amount of CB powder was placed inside a $50 \mathrm{~mL}$ bottle together with $15 \mathrm{~g}$ of TEP and was then sonicated with an ultrasonic bath for $30 \mathrm{~min}$ at $25{ }^{\circ} \mathrm{C}$ to improve the dispersion.

The membranes were prepared via the NIPS technique, by dissolving a commercial PVDF (Solef ${ }^{\circledR}$ 6010, Solvay Specialty Polymers-Bollate, Italy, Mw $300 \mathrm{kDa}$ ) dissolved in the $\mathrm{CB} / \mathrm{TEP}$ dispersions to create a $\mathrm{CB}$ doped solution and provide the desired photothermal properties to the final membrane. A $300 \mu \mathrm{m}$ thick film of dope solution was cast on a commercial PET non-woven support (Viledon ${ }^{\circledR}$ FO-2401, Freudenberg-Weinheim, Germany) and then immersed in a weak coagulation bath containing ethanol $96 \mathrm{v} / \mathrm{v} \%$ (VWR International-Radnor, PA, USA). After $2 \mathrm{~h}$, the membranes were removed from the nonsolvent, washed with deionized water to remove ethanol from the pores and finally dried overnight at room temperature. Table 1 summarizes the preparation conditions of all of the membranes assessed. In the sample name, the first part refers to the polymer concentration in the dope solution, while the second part refers to the CB concentration.

Table 1. Preparation conditions of the tested membranes.

\begin{tabular}{|c|c|c|c|c|}
\hline Sample & 145_0 & 145_2 & $145 \_5$ & 145_75 \\
\hline CB concentration ${ }^{1}[w t \%]$ & 0 & 2.0 & 5.0 & 7.5 \\
\hline PVDF concentration ${ }^{2}[\mathrm{wt} \%]$ & \multicolumn{4}{|c|}{14.5} \\
\hline Solvent & \multicolumn{4}{|c|}{ TEP } \\
\hline Non-solvent & \multicolumn{4}{|c|}{$\mathrm{EtOH} 96 v / v \%$} \\
\hline Casting temperature $\left[{ }^{\circ} \mathrm{C}\right]$ & \multicolumn{4}{|c|}{25} \\
\hline Casting thickness $[\mu \mathrm{m}]$ & \multicolumn{4}{|c|}{300} \\
\hline
\end{tabular}

${ }^{1}$ with respect to PVDF mass; ${ }^{2}$ with respect to the solution mass.

\subsection{Light Absorption Measurements}

Absolute hemispherical reflectance spectra of the membranes were acquired using an UV/VIS/NIR spectrophotometer (Lambda9, Perkin Elmer-Waltham, MA, USA) equipped 
with a $150 \mathrm{~mm}$ integrating sphere. The inspected spectral range was between 200 and $2700 \mathrm{~nm}$. A $\mathrm{TiO}_{2}$ coated layer was used as a blank sample.

For each sample, four spectra were registered, rotating the specimen by $90^{\circ}$ each time. The four spectra allowed for estimating the surface homogeneity of the sample and compensating for any possible influence related to defects in the sample and its surface roughness. The final results were reported as absorbance values, which were then calculated as the mean of the four measurements.

The photothermal properties of the dry membranes were assessed by measuring the surface temperature change over time after a light source was turned on with the setup schematized in Figure 1.

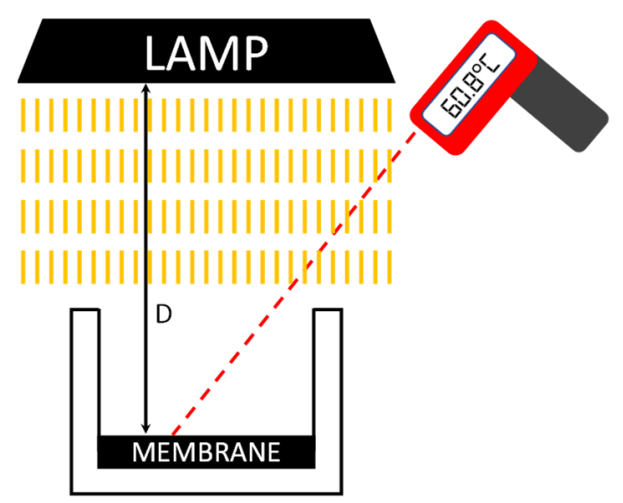

Figure 1. Sketch of the setup used for surface temperature measurements.

The samples $\left(17.5 \mathrm{~cm}^{2}\right.$ surface area) were put in a special container made of expanded PVC - used to avoid heat losses related to conduction through the membrane-and placed under the light source at a distance (D) of $9 \mathrm{~cm}$. The surface temperature was determined using an infrared thermometer (RS-8662, RS PRO-Kuala Lumpur, Malaysia).

\subsection{Membrane Performance Evaluation}

The prepared membranes were tested using a DSMD setup expressly built in the laboratory for this application. VMD configuration was selected because of the high distillate flux that it guarantees in comparison to other MD modes. Figure 2 reports a scheme of this apparatus.

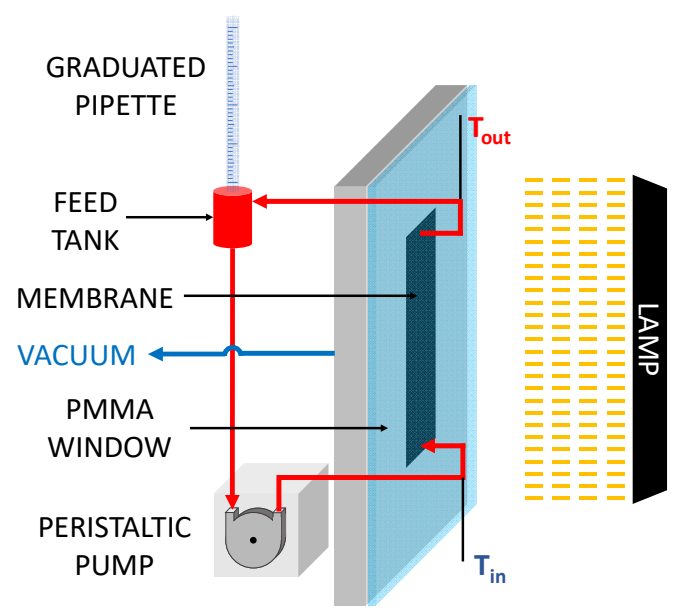

Figure 2. Sketch of the DSMD setup used to test the photothermal membranes.

The membrane cell was equipped with a transparent polymethylmethacrylate (PMMA) film that allowed the passage of simulated solar light. The feed channel was $3 \mathrm{~mm}$ thick and the peristaltic pump used for recirculating the liquid had a flow rate of $40 \mathrm{~mL} / \mathrm{min}$, 
therefore, the velocity inside the membrane cell was $53 \mathrm{~cm} / \mathrm{min}$ and the residence time was almost $15 \mathrm{~s}$. The concentrate was recirculated to the feed tank continuously. Two K type thermocouples, connected to a digital data logger (HD2128.1, Deltaohm-Selvazzano Dentro, Italy), were mounted at the feed inlet and at the concentrate outlet to measure the liquid temperature gradient along the membrane module.

The driving force was applied by connecting the support side of the cell (grey in Figure 2) to a vacuum pump that maintained the permeate side at 20 mbar (absolute pressure). Before the start of each test, a precise amount of deionized water $(40 \mathrm{~mL})$ was put in a closed tank equipped with a graduated pipette that was used to measure the distillate flux through the lowering of the liquid level after a set time interval (60 min).

The only heat source for these tests was a light source mounted $7 \mathrm{~cm}$ away from the membrane surface. Each membrane was tested using two different light sources: a traditional $75 \mathrm{~W}$ incandescent light bulb (OSRAM-Munich, Germany), and a $100 \mathrm{~W}$ solar spectrum LED light (Shenzhen Milyn Technology-Guangdong, China). A reference test was also performed in order to evaluate the membrane performance without any external light source. In this case, the membrane cell was covered with an aluminum foil during operation.

Figure 3 reports the emission spectra of the two lamps used, compared with sunlight.

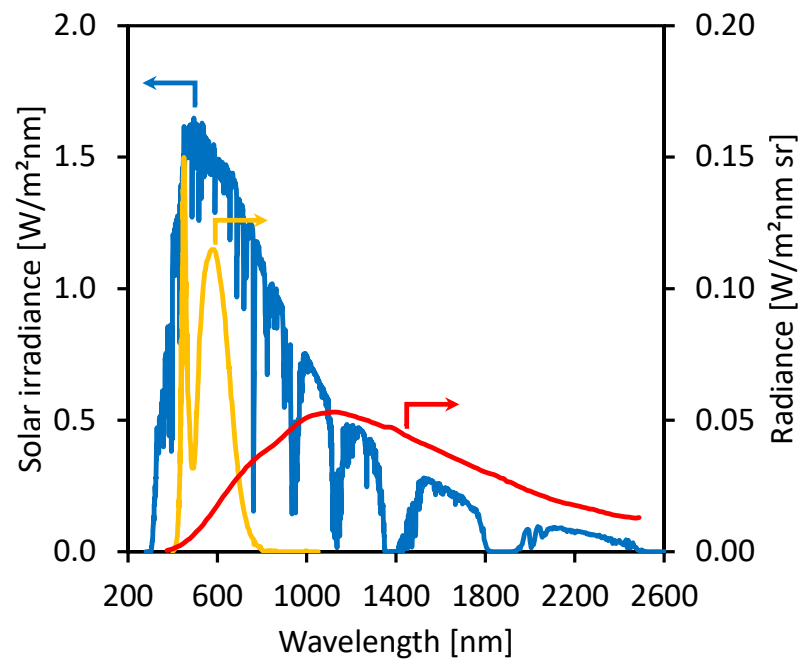

Figure 3. ASTMG 173 AM1.5 solar emission spectrum (blue), and common incandescent light bulb (red) and natural white $100 \mathrm{~W}$ LED lamp (yellow) spectra [39]. Note the different ordinate scales.

The irradiance of the two light sources at different distances ranging between $4 \mathrm{~cm}$ and approximately $40 \mathrm{~cm}$ was determined using a solar power meter (ISM 410, RS PRO-Kuala Lumpur, Malaysia). The measurements were performed by placing the lamp vertically above the sensor.

Table 2 summarizes the operating conditions used to test the DSMD performance of the prepared membranes.

Table 2. DSMD tests conditions.

\begin{tabular}{cc}
\hline Tested Feeds & Deionized Water \\
\hline Light distance & $7 \mathrm{~cm}$ \\
\hline Feed temperature & $24^{\circ} \mathrm{C}$ \\
\hline Feed flow rate & $40 \mathrm{~mL} / \mathrm{min}$ \\
\hline Membrane area & $30 \mathrm{~cm}^{2}$ \\
\hline Vacuum degree & $20 \mathrm{mbar}$ \\
\hline
\end{tabular}




\section{Results and Discussion}

\subsection{Light Source Characterization}

A major system characteristic to be investigated when using light sources to simulate the solar energy is the irradiated power per unit area, which is called irradiance. The irradiance then must be compared to the average yearly standard solar conditions at the sea level (about $1000 \mathrm{~W} / \mathrm{m}^{2}$ ) [40]. Figure 4 reports the values collected at different distances for the two lamps employed in this work.
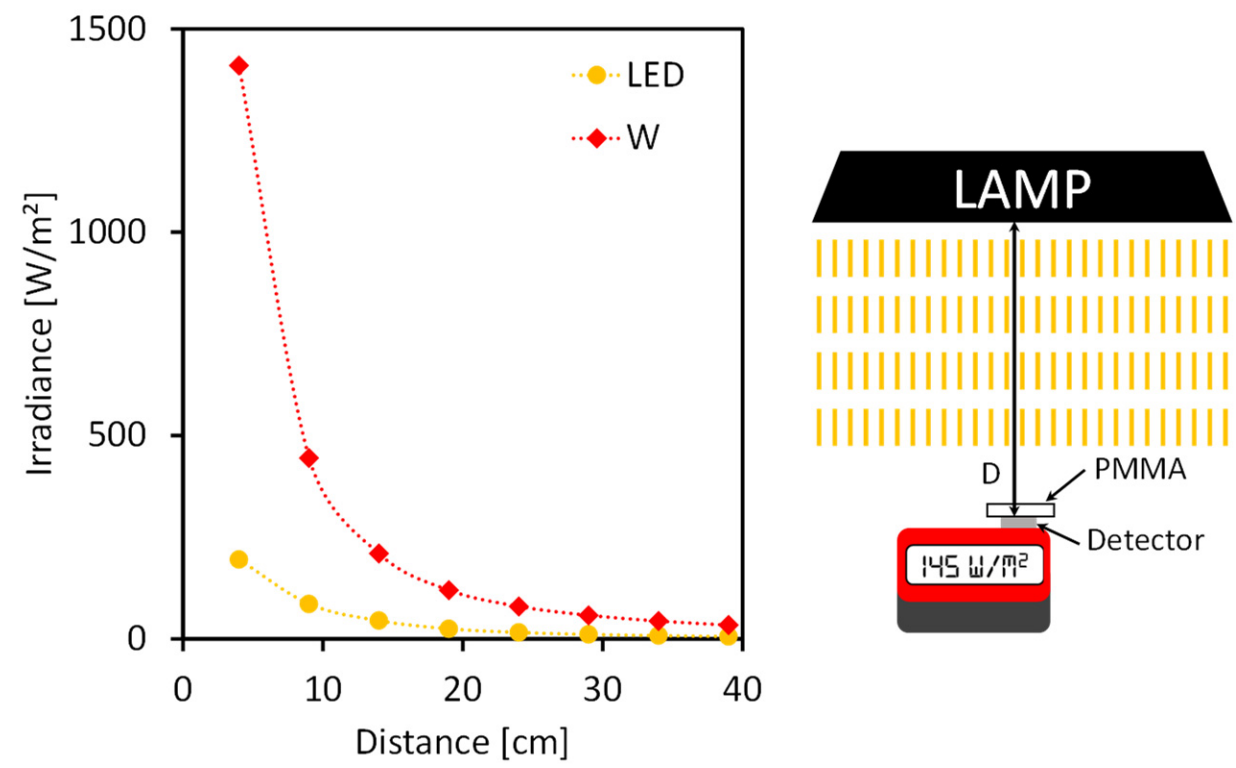

Figure 4. Irradiance of the two used lamps, LED and incandescent, W, through a PMMA window (left) and measuring setup scheme (right).

The traditional incandescent lamp (red) was able to provide higher power than the solar-like LED lamp (yellow). However, both light sources showed a hyperbolic-like decrease of the irradiance value as the distance between the source and the sensor was increased. This imposed a strict control on the distance between the lamp and the membrane surface in the successive VMD tests.

\subsection{Light Absorption of Membranes}

Common cells for traditional MD processes are generally made of non-transparent materials, such as stainless steel or plastic, owing to their ability to withstand the feed temperature and salinity. However, such materials are not transparent to UV and visible radiation. Since membranes for DSMD application must be able to absorb light and to transform the energy captured in the available heat, their surface should be allowed to be irradiated with light. Among all of the transparent material, PMMA was selected for this purpose during the VMD cell assembling due to its low absorbance in a broad wavelength interval, as reported in Figure 5. 


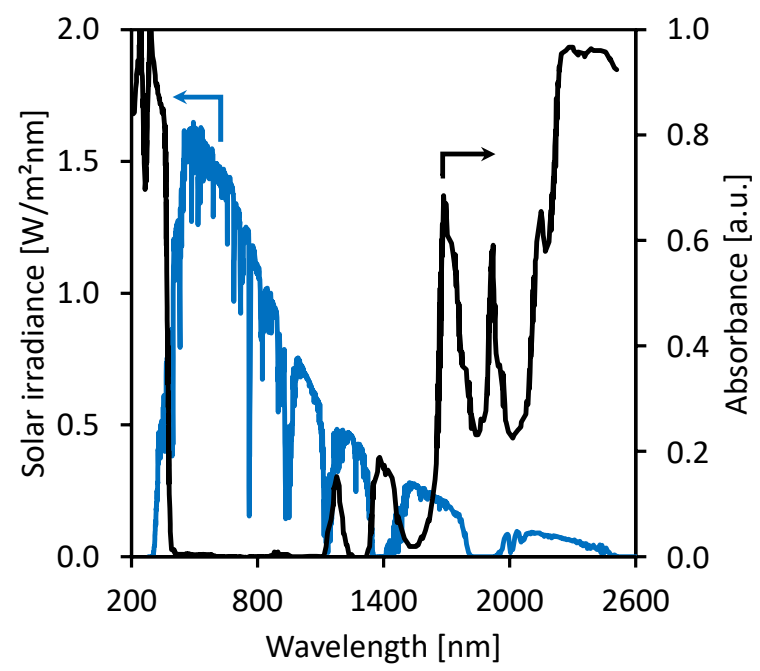

Figure 5. Light absorbance of the VMD cell window made of PMMA (black) and ASTMG 173 AM1.5 solar emission spectrum (blue).

Spectral solar irradiance was shown and PMMA proved to be completely transparent in the majority of the wavelength interval of solar emission spectrum; it presented intense absorption bands only below $400 \mathrm{~nm}$ and over $1300 \mathrm{~nm}$. In the interval 400-1300 nm, almost $90 \%$ of the whole solar irradiance is emitted. Therefore, PMMA was considered an ideal material to create the window required in this special VMD cell.

When the membrane surface is irradiated with light, the obvious key parameter for DSMD application is the membrane photoactivity that can be estimated by measuring the absorbance in the UV/visible wavelength interval. These measurements were performed using a Perkin Elmer Lambda9 UV/VIS/NIR spectrometer in the spectral range between 200 and $1400 \mathrm{~nm}$ (recall the comments on Figure 5). Figure 6 reports the registered spectra for the four membranes prepared at increasing $\mathrm{CB}$ loading as well as for the $\mathrm{CB}$ as such.

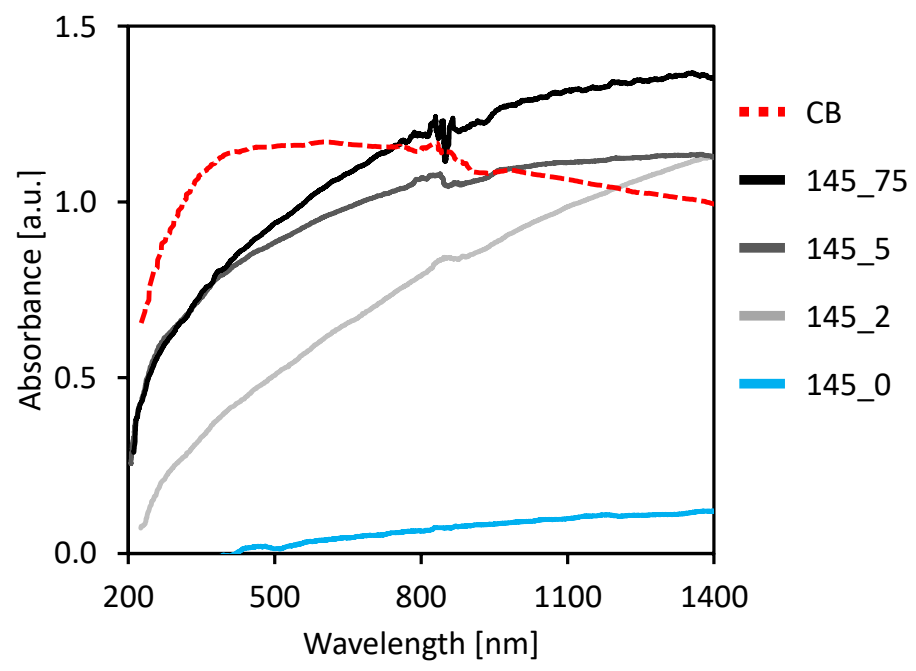

Figure 6. UV/VIS/NIR absorption spectra of the four membranes and of carbon black.

CB (red dotted line in Figure 6) showed a broad absorption band in the whole wavelength interval investigated with a wide maximum in the visible light range.

On the other hand, the pure PVDF membrane (blue line in Figure 6) was characterized by a far less intense absorption in the same wavelength interval. Most of the solar radiation evidently was reflected by the white surface of the membrane.

The introduction of $\mathrm{CB}$ inside the dope solution greatly increased the light absorption of the samples in the UV/VIS/NIR spectral region of interest. In particular, the absorbance 
showed an impressive enhancement, moving from 145_0 sample to 145_2 and then 145_5, i.e., with an increase in $\mathrm{CB}$ concentration.

Figure 6 illustrates that the unloaded PVDF membrane had a very low ability to capture solar energy with a slight increase at higher wavelengths. The 145_2 sample partly retains the effect of the PVDF matrix, showing an almost linear growth of the absorbance, but, in contrast, it reaches noticeable values at higher wavelengths. The samples 145_5 and 145_75 exhibited a sharp increment of absorbance at lower wavelengths and their spectra appeared quite similar to that of the $\mathrm{CB}$ as such. Moreover, there does not seem to be a substantial difference between the behaviors of the two membranes.

These features were reflected in the photothermal activity shown by the various samples. Figure 7 reports the surface temperature change over time when the membrane surface was exposed to the two different lamps (A: LED lamp, B: incandescent lamp).
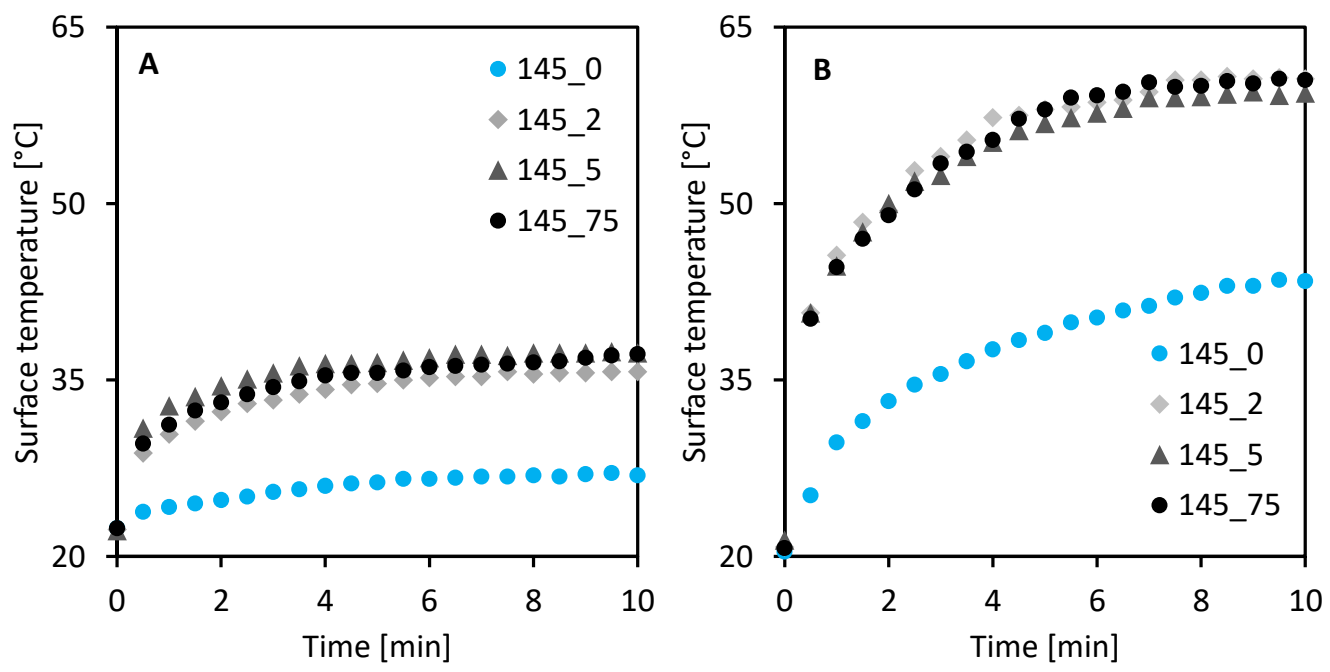

Figure 7. Membrane surface temperature change using (A) LED lamp and (B) incandescent lamp.

The two lamps were characterized by different emission spectra (Figure 3), as well as a different irradiance (Figure 4). These tests were performed by placing the light source $9 \mathrm{~cm}$ above the membrane, meaning that the LED irradiance was around $90 \mathrm{~W} / \mathrm{m}^{2}$, while the incandescent lamp provided about $435 \mathrm{~W} / \mathrm{m}^{2}$ to the membrane surface. This difference was confirmed by the surface temperature measurements. Using the LED light (Figure 7A), the $\mathrm{CB}$ loaded membrane's temperature rose almost instantly from about $20^{\circ} \mathrm{C}$ to $30^{\circ} \mathrm{C}$ and continued to increase for several minutes reaching a stable value at around $35^{\circ} \mathrm{C}$. The incandescent lamp, thanks to its higher irradiance at an equal distance, showed a similar trend but higher temperatures were developed on the membrane surface that reached for all the membranes values of about $60^{\circ} \mathrm{C}$. In both cases $\mathrm{A}$ and $\mathrm{B}$, adding $\mathrm{CB}$ to the dope solution generated a great difference between unloaded and loaded membrane and an almost $40 \%$ temperature increase was obtained for all of the samples. However, the CB concentration had only a marginal effect on the surface temperature of the membrane since, when irradiated under the same conditions, all of the CB-loaded membranes performed similarly. Table 3 reports some literature data of the maximum surface temperature reached by photoactive membranes irradiated with solar-like light sources. 
Table 3. Literature data of surface temperature of photoactive membranes.

\begin{tabular}{ccccc}
\hline Membrane Type & $\begin{array}{c}\text { Photoactive } \\
\text { Material }\end{array}$ & $\begin{array}{c}\text { Irradiation } \\
{\left[\mathbf{W} / \mathbf{m}^{\mathbf{2}}\right]}\end{array}$ & $\begin{array}{c}\text { Surface Temperature } \\
{\left[{ }^{\circ} \mathbf{C}\right]}\end{array}$ & Ref. \\
\hline Coated PVDF & $\begin{array}{c}\text { Carbon } \\
\text { nanotubes }\end{array}$ & 1000 & 70 & {$[33]$} \\
Coated PVDF & Carbon black & 1000 & 48 & {$[34]$} \\
Coated PVDF & Polydopamine & 750 & 35 & {$[41]$} \\
Mixed matrix PVDF & Carbon black & 435 & 60 & This work \\
\hline
\end{tabular}

While it is almost impossible to find results obtained under identical conditions, the data reported in Table 3 highlight the excellent performance of the membranes developed in this work. In fact, despite being tested with a less powerful light source, the samples prepared directly including CB inside the PVDF matrix were able to reach temperatures higher than—or at least similar to—-the ones obtained with coated membranes.

\subsection{Distillation Performance}

The membrane distillation performance was evaluated using the setup shown in Figure 2. The feed temperatures were registered over a one-hour test for each light source and the registered differences during this time span, $\Delta \mathrm{T}_{\mathrm{m}}$, are reported in Figure 8 , and are expressed as follows:

$$
\Delta \mathrm{T}_{\mathrm{m}}=\frac{\left(\mathrm{T}_{\mathrm{out}_{60}}-\mathrm{T}_{\mathrm{out}_{0}}\right)+\left(\mathrm{T}_{\mathrm{in}_{60}}-\mathrm{T}_{\mathrm{in}_{0}}\right)}{2}
$$

where the subscripts $\mathrm{in}_{60}$ and out $_{60}$ indicate the liquid temperature at the cell inlet and

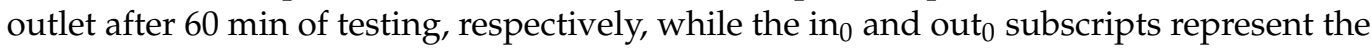
same values recorded at the start of the tests.

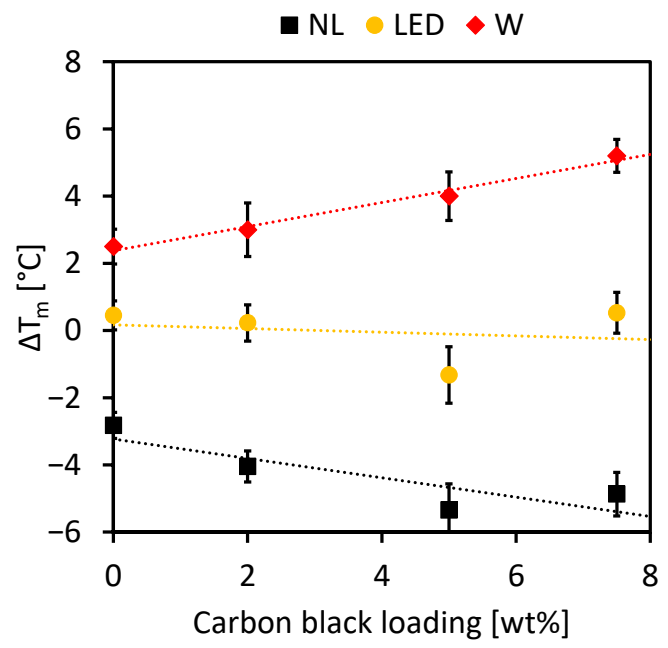

Figure 8. Mean feed temperature difference between MD test end and start with no light (NL, black), LED lamp (yellow) and incandescent light bulb (W, red).

For all of the samples, the test performed without light (black in Figure 8) showed a decrease of the feed temperature over time. In the absence of any external energy supply the latent heat absorbed by water evaporation at the membrane surface caused an appreciable feed cooling.

The $\Delta \mathrm{T}_{\mathrm{m}}$ values obtained when the membranes were irradiated with a light source exhibited a completely different trend. The LED lamp (yellow in Figure 8) was able to counteract the heat loss related to water evaporation but, since its irradiance was quite weak (see Figure 4), the feed temperature remained almost constant during the test. On the other hand, the incandescent lamp (red in Figure 8) provided more energy to the system 
and the feed temperature was increased during the time span of DSMD operation for all of the tested samples. These findings are in agreement with the data reported in Figure 7A,B.

The beneficial effect of the light irradiation obviously affected the distillate fluxes as expected. Figure 9 summarizes the results concerning the MD tests for all of the samples and all of the lighting options.
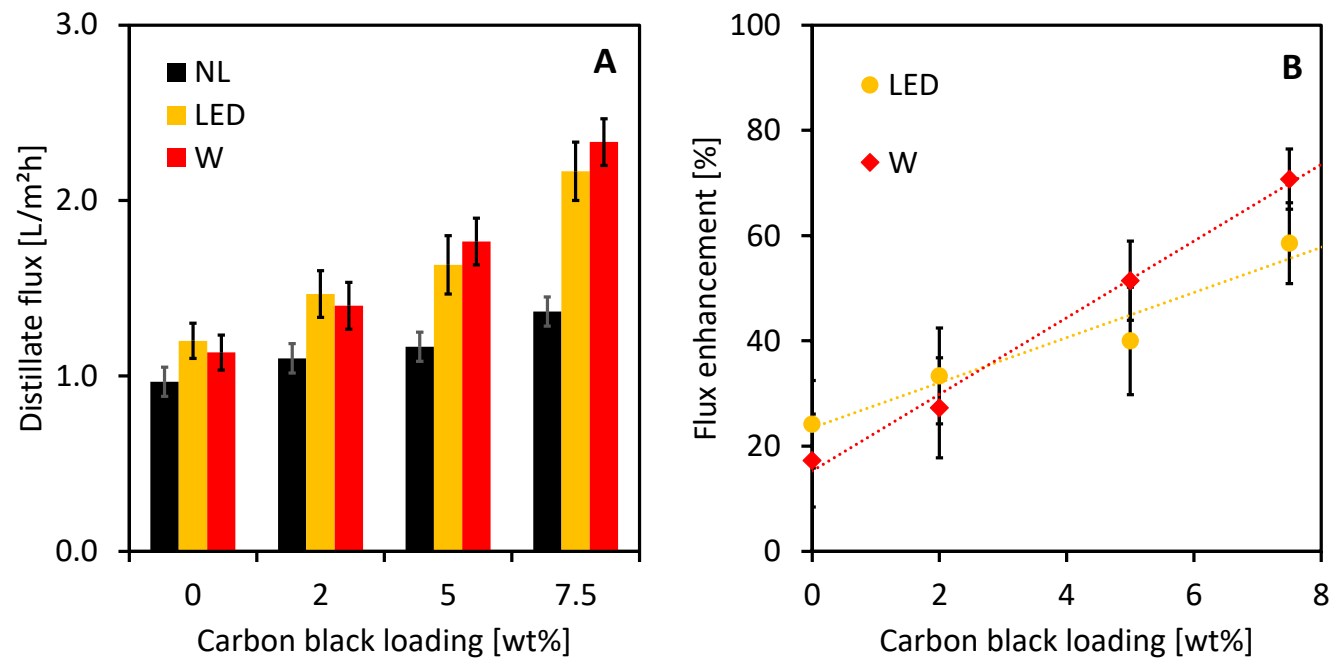

Figure 9. (A) mean distillate flux and (B) flux enhancement registered during the MD tests with no light (black), LED lamp (yellow) and incandescent light bulb (red).

The distillate fluxes (Figure 9A) obtained during the tests without light sources confirmed the results obtained during a previous work carried out in our laboratory [37]. That study also revealed that the addition of $C B$ to the dope solution enhances both the pore size and porosity of the membrane and therefore can induce an increase in the membrane permeability. It was found that introducing a proper amount of CB led to an increment of both pore size - which passed from about 100 (sample 145_0) to about $850 \mathrm{~nm}$ (sample 145_75) - and overall porosity, which rose from $76 \%$ to $87 \%$. Both of these parameters strongly affect the membrane mass transfer resistance; it is well known that larger pore size and porosity values provide higher transmembrane vapor fluxes during MD operation. Moreover, in the same study, it was demonstrated that higher CB loadings led to an enhancement of the matrix hydrophobicity, preventing negative phenomena, such as pore flooding. For all of these reasons, even without light irradiation the distillate flux of the 145_75 sample was somewhat higher compared to the one registered for the pure PVDF membrane (145_0).

In this work, using only light as the energy supply for feed heating was proved to be effective for all of the samples prepared. In fact, under irradiation, the distillate flux was always enhanced. This effect became more intense as the CB loading in the dope solution was raised from $2 \mathrm{wt} \%$ to $7.5 \mathrm{wt} \%$. The flux enhancement $(\mathrm{FE} \%)$ reported in Figure $9 \mathrm{~B}$ was calculated using the following equation:

$$
\mathrm{FE} \%=\frac{\left(\mathrm{J}_{\text {Light }}-\mathrm{J}_{\mathrm{NL}}\right)}{\mathrm{J}_{\mathrm{NL}}} \cdot 100
$$

where $\mathrm{J}_{\text {Light }}$ is the distillate flux obtained irradiating the membrane with a light source while $\mathrm{J}_{\mathrm{NL}}$ is the distillate flux without irradiation.

Increasing the $\mathrm{CB}$ concentration improved the light absorbance of the membranes (Figure 6) and boosted the feed temperature rise on the membrane surface. As a consequence, the vapor pressure at the pore entrance got higher and enhanced the driving force of the process. The distillate flux increment became more evident as the CB loading grew. It can be seen from Figure 9B that, for the 145_75 sample, a distillate flux enhancement of up 
to $60 \%$ and $70 \%$ was reached when the LED or incandescent lamps were used, respectively. Table 4 reports a VMD performance comparison between the membranes prepared in this work and a sample tested by Ma et al. [42] who coated a PTFE membrane with carbon nanotubes.

Table 4. VMD performance comparison.

\begin{tabular}{ccccccc}
\hline $\begin{array}{c}\text { Membrane } \\
\text { Type }\end{array}$ & $\begin{array}{c}\text { Photoactive } \\
\text { Material }\end{array}$ & $\begin{array}{c}\text { Irradiation } \\
{\left[\mathbf{W} / \mathbf{m}^{2}\right]}\end{array}$ & $\begin{array}{c}\text { Vacuum } \\
{[\mathbf{m b a r}]}\end{array}$ & $\begin{array}{c}\text { Feed } \\
\text { Temperature } \\
{\left[{ }^{\circ} \mathbf{C}\right]}\end{array}$ & $\begin{array}{c}\text { Distillate } \\
\text { Flux } \\
{\left[\mathbf{L} / \mathbf{m}^{2} \mathbf{h}\right]}\end{array}$ & $\begin{array}{c}\text { Ref. } \\
\text { Coated PTFE }\end{array}$ \\
$\begin{array}{c}\text { Carbon } \\
\text { nanotubes } \\
\begin{array}{c}\text { Mixed matrix } \\
\text { PVDF }\end{array}\end{array}$ & 750 & 50 & 20 & 2.8 & 2.3 & This work \\
\hline
\end{tabular}

The two membranes were tested under similar conditions in terms of vacuum pressure, feed temperature and light irradiance and showed comparable distillate fluxes. These results confirmed the potential of mixed matrix membranes for DSMD application. The advantages of preparing a single layer membrane are, primarily, the easier procedure required and the more robust final structure. On the contrary, when a commercial membrane is coated with photothermal conversion materials, a poor adhesion between the support material and the surface skin can induce the delamination phenomena that can undermine the integrity and the performance of the membrane.

\section{Conclusions}

A simple and innovative preparation method to produce photoactive membranes was proposed, which involves incorporating the light absorbing filler directly inside the membrane matrix. The preparation procedure was based on a traditional NIPS technique and the filler was first dispersed in the polymeric dope solution. In line with the goals of an environmentally sustainable and safe membrane preparation process, a green solvent, triethyl phosphate, was used. The main novelty in this work was incorporating the selected filler, carbon black, inside the entire polymeric matrix. This particular formulation allowed to produce favorable outcomes on the internal membrane structure. Nearly all of the strategies to achieve surface heating MD are currently based on membrane surface modification by various techniques. However, based on our findings, inclusion of carbon black nanoparticles inside the whole membrane structure seems to have multiple beneficial effects on the membrane performance. In fact, the filler acts not only on the photothermal properties enhancing the light absorbance, but also on the membrane morphology increasing porosity and pores size. These latter characteristics, which are very important to reduce the membrane mass transfer resistance, were improved with the rising CB content.

In terms of photothermal properties, membranes prepared with a sufficient CB loading were able to reach satisfactory surface temperatures when exposed to light sources.

On the whole, as the carbon black loading was raised, the effectiveness during direct solar membrane distillation operation was improved and the membranes prepared with the highest $\mathrm{CB}$ concentration showed the best flux enhancement factor.

Author Contributions: Conceptualization, A.C. and M.P.; methodology, M.P.; investigation, M.A., R.F., E.A.M. and M.P.; writing-original draft preparation, M.P. and C.C.; writing-review and editing, A.C. and C.C.; visualization, M.P.; supervision, A.C. and C.C. All authors have read and agreed to the published version of the manuscript.

Funding: This research received no external funding.

Conflicts of Interest: The authors declare no conflict of interest. 


\section{References}

1. Lawson, K.W.; Lloyd, D.R. Membrane distillation. J. Membr. Sci. 1997, 124, 1-25. [CrossRef]

2. Khayet, M.; Matsuura, T. Membrane Distillation: Principles and Applications; Elsevier: Amsterdam, The Netherlands, 2011; ISBN 9780444531261.

3. Schofield, R.W.W.; Fane, A.G.G.; Fell, C.J.D.J.D. Heat and mass transfer in membrane distillation. J. Membr. Sci. 1987, 33, 299-313 [CrossRef]

4. Alkhudhiri, A.; Darwish, N.; Hilal, N. Membrane distillation: A comprehensive review. Desalination 2012, 287, 2-18. [CrossRef]

5. Rezaei, M.; Warsinger, D.M.; Lienhard, V.J.H.; Duke, M.C.; Matsuura, T.; Samhaber, W.M. Wetting phenomena in membrane distillation: Mechanisms, reversal, and prevention. Water Res. 2018, 139, 329-352. [CrossRef]

6. $\quad$ Eykens, L.; De Sitter, K.; Dotremont, C.; Pinoy, L.; Van Der Bruggen, B. How to Optimize the Membrane Properties for Membrane Distillation: A Review. Ind. Eng. Chem. Res. 2016, 55, 9333-9343. [CrossRef]

7. Schneider, K.; Hölz, W.; Wollbeck, R.; Ripperger, S. Membranes and modules for transmembrane distillation. J. Membr. Sci. 1988, 39, 25-42. [CrossRef]

8. Pagliero, M.; Khayet, M.; García-Payo, C.; García-Fernández, L. Hollow fibre polymeric membranes for desalination by membrane distillation technology: A review of different morphological structures and key strategic improvements. Desalination 2021, 516, 115235. [CrossRef]

9. Li, B.; Sirkar, K.K.; York, O.H. Novel Membrane and Device for Direct Contact Membrane Distillation-Based Desalination Process Ind. Eng. Chem. Res. 2004, 43, 5300-5309. [CrossRef]

10. Xu, Y.; Zhu, B.K.; Xu, Y.Y. Pilot test of vacuum membrane distillation for seawater desalination on a ship. Desalination 2006, 189, 165-169. [CrossRef]

11. Matsuyama, H.; Berghmans, S.; Lloyd, D.R. Formation of hydrophilic microporous membranes via thermally induced phase separation. J. Membr. Sci. 1998, 142, 213-224. [CrossRef]

12. Eykens, L.; De Sitter, K.; Dotremont, C.; Pinoy, L.; Van der Bruggen, B. Characterization and performance evaluation of commercially available hydrophobic membranes for direct contact membrane distillation. Desalination 2016, 392, 63-73. [CrossRef]

13. Ghani, F.A.; Hamzah, K.; Norharyati, W.; Salleh, W.; Mohamed, H. Preparation and characterization of PTFE flat sheet membrane: Effect of sodium benzoate content. Malays. J. Fundam. Appl. Sci. 2017, 13, 598-601. [CrossRef]

14. Pagliero, M.; Bottino, A.; Comite, A.; Costa, C. Novel hydrophobic PVDF membranes prepared by nonsolvent induced phase separation for membrane distillation. J. Membr. Sci. 2020, 596, 117575. [CrossRef]

15. Marino, T.; Russo, F.; Figoli, A. The Formation of Polyvinylidene Fluoride Membranes with Tailored Properties via Vapour/NonSolvent Induced Phase Separation. Membranes 2018, 8, 71. [CrossRef] [PubMed]

16. Khayet, M.; Feng, C.Y.; Khulbe, K.C.; Matsuura, T. Preparation and characterization of polyvinylidene fluoride hollow fiber membranes for ultrafiltration. Polymer 2002, 43, 3879-3890. [CrossRef]

17. Pagliero, M.; Comite, A.; Soda, O.; Costa, C. Effect of support on PVDF membranes for distillation process. J. Membr. Sci. 2021, 635, 119528. [CrossRef]

18. Hubadillah, S.K.; Othman, M.H.D.; Matsuura, T.; Rahman, M.A.; Jaafar, J.; Ismail, A.F.; Amin, S.Z.M. Green silica-based ceramic hollow fiber membrane for seawater desalination via direct contact membrane distillation. Sep. Purif. Technol. 2018, 205, 22-31. [CrossRef]

19. Pagliero, M.; Bottino, A.; Comite, A.; Costa, C. Silanization of tubular ceramic membranes for application in membrane distillation J. Membr. Sci. 2020, 601, 117911. [CrossRef]

20. Fang, H.; Gao, J.F.; Wang, H.T.; Chen, C.S. Hydrophobic porous alumina hollow fiber for water desalination via membrane distillation process. J. Membr. Sci. 2012, 403-404, 41-46. [CrossRef]

21. Eykens, L.; De Sitter, K.; Dotremont, C.; Pinoy, L.; Van der Bruggen, B. Membrane synthesis for membrane distillation: A review. Sep. Purif. Technol. 2017, 182, 36-51. [CrossRef]

22. Comite, A.; Pagliero, M.; Costa, C. Wastewater treatment by membrane distillation. In Current Trends and Future Developments on (Bio-) Membranes; Elsevier: Amsterdam, The Netherlands, 2020; pp. 3-34, ISBN 9780128168240.

23. Drioli, E.; Ali, A.; Macedonio, F. Membrane distillation: Recent developments and perspectives. Desalination 2015, 356, 56-84 [CrossRef]

24. González, D.; Amigo, J.; Suárez, F. Membrane distillation: Perspectives for sustainable and improved desalination. Renew. Sustain. Energy Rev. 2017, 80, 238-259. [CrossRef]

25. Rodríguez-Maroto, J.M.; Martínez, L. Bulk and measured temperatures in direct contact membrane distillation. J. Membr. Sci. 2005, 250, 141-149. [CrossRef]

26. Tan, Y.Z.; Chandrakant, S.P.; Ang, J.S.T.; Wang, H.; Chew, J.W. Localized induction heating of metallic spacers for energy-efficient membrane distillation. J. Membr. Sci. 2020, 606, 118150. [CrossRef]

27. Anvari, A.; Kekre, K.M.; Azimi Yancheshme, A.; Yao, Y.; Ronen, A. Membrane distillation of high salinity water by induction heated thermally conducting membranes. J. Membr. Sci. 2019, 589, 117253. [CrossRef]

28. Said, I.A.; Wang, S.; Li, Q. Field Demonstration of a Nanophotonics-Enabled Solar Membrane Distillation Reactor for Desalination. Ind. Eng. Chem. Res. 2019, 58, 18829-18835. [CrossRef]

29. Bamasag, A.; Alqahtani, T.; Sinha, S.; Ghaffour, N.; Phelan, P. Experimental investigation of a solar-heated direct contact membrane distillation system using evacuated tube collectors. Desalination 2020, 487, 114497. [CrossRef] 
30. Chandrashekara, M.; Yadav, A. Water desalination system using solar heat: A review. Renew. Sustain. Energy Rev. 2017, 67, 1308-1330. [CrossRef]

31. Zaragoza, G.; Andrés-Mañas, J.A.; Ruiz-Aguirre, A. Commercial scale membrane distillation for solar desalination. NPJ Clean Water 2018, 1, 1-6. [CrossRef]

32. Karanikola, V.; Moore, S.E.; Deshmukh, A.; Arnold, R.G.; Elimelech, M.; Sáez, A.E. Economic performance of membrane distillation configurations in optimal solar thermal desalination systems. Desalination 2019, 472, 114164. [CrossRef]

33. Huang, J.; Hu, Y.; Bai, Y.; He, Y.; Zhu, J. Novel solar membrane distillation enabled by a PDMS/CNT/PVDF membrane with localized heating. Desalination 2020, 489, 114529. [CrossRef]

34. Chen, Y.-R.; Xin, R.; Huang, X.; Zuo, K.; Tung, K.-L.; Li, Q. Wetting-resistant photothermal nanocomposite membranes for direct solar membrane distillation. J. Membr. Sci. 2021, 620, 118913. [CrossRef]

35. Wu, J.; Zodrow, K.R.; Szemraj, P.B.; Li, Q. Photothermal nanocomposite membranes for direct solar membrane distillation. J. Mater. Chem. A 2017, 5, 23712-23719. [CrossRef]

36. Dongare, P.D.; Alabastri, A.; Pedersen, S.; Zodrow, K.R.; Hogan, N.J.; Neumann, O.; Wu, J.; Wang, T.; Deshmukh, A.; Elimelech, M.; et al. Nanophotonics-enabled solar membrane distillation for off-grid water purification. Proc. Natl. Acad. Sci. USA 2017, 114, 6936-6941. [CrossRef]

37. Pagliero, M.; Comite, A.; Costa, C.; Rizzardi, I.; Soda, O. A Single Step Preparation of Photothermally Active Polyvinylidene Fluoride Membranes Using Triethyl Phosphate as a Green Solvent for Distillation Applications. Membranes 2021, 11, 896. [CrossRef] [PubMed]

38. Lázaro, M.J.; Calvillo, L.; Celorrio, V.; Pardo, J.I.; Perathoner, S.; Moliner, R. Study and Application of Carbon Black Vulcan XC-72R in Polymeric Electrolyte Fuel Cells; Nova Science Publishers, Inc.: New York, NY, USA, 2011.

39. Elvidge, C.D.; Keith, D.M.; Tuttle, B.T.; Baugh, K.E. Spectral identification of lighting type and character. Sensors 2010, 10, 3961-3988. [CrossRef]

40. Jessen, W.; Wilbert, S.; Gueymard, C.A.; Polo, J.; Bian, Z.; Driesse, A.; Habte, A.; Marzo, A.; Armstrong, P.R.; Vignola, F.; et al. Proposal and evaluation of subordinate standard solar irradiance spectra for applications in solar energy systems. Sol. Energy 2018, 168, 30-43. [CrossRef]

41. Wu, X.; Jiang, Q.; Ghim, D.; Singamaneni, S.; Jun, Y.-S. Localized heating with a photothermal polydopamine coating facilitates a novel membrane distillation process. J. Mater. Chem. A 2018, 6, 18799-18807. [CrossRef]

42. Ma, Q.; Xu, Z.; Wang, R.; Poredoš, P. Distributed vacuum membrane distillation driven by direct-solar heating at ultra-low temperature. Energy 2022, 239, 121891. [CrossRef] 